\title{
4
}

\section{(DES)CAMINHOS DO SISTEMA BRASILEIRO DE COTAS UNIVERSITÁRIAS}

Discharges of the brazilian system of university quota

\author{
Mariana Rosa Alves Ladeira* \\ Hilda Maria Gonçalves da Silva** \\ (c) (i)(2)
}

\section{RESUMO}

O presente artigo objetiva apresentar a trajetória que culminou no atual sistema de cotas brasileiro. O artigo possui abordagem qualitativa, e utilizou de pesquisa bibliográfica e documental para sua discussão. Sabe-se que retomar a historicidade de ações afirmativas é também ampliar o debate dos limites e possibilidades do acesso ao ensino superior público federal. Assim como é primordial o entendimento da história para balizar o processo de conformação da agenda e conflitos de interesses do sistema de cotas, que levaram a aprovação da Lei n. 12.711, de 29 de agosto de 2012. O estudo faz parte de uma dissertação de mestrado, financiada pela CAPES, concluída em 2017. Conclui-se que a pesquisa abre caminhos qualitativos para novas pesquisas, assim como contribui como aporte teórico para a reflexão do acesso à educação superior pública.

\section{PALAVRAS-CHAVE}

Cotas. Educação superior. Ações afirmativas.

\section{ABSTRACT}

The present article aims to present the trajectory that culminated in the current Brazilian quota system. The article has a qualitative approach, and used bibliographical and documentary research for its discussion. It is known that to return to the historicity of affirmative actions is also to expand the debate about the limits and possibilities of access

\footnotetext{
* Assistente Social. Doutoranda do Programa de Pós Graduação em Serviço Social da UNESP/. Docente na área de Desenvolvimento Social do Senac/Jaboticabal. R. Vinte e Quatro de Maio, 831, Centro, Jaboticabal (SP), CEP.: 14870-350. E-mail: <mari.ladeira@hotmail.com>. ORC ID: <https://orcid.org/0000-0002-37067415>.

${ }^{* *}$ Historiadora. Doutora em Educação Escolar (UNESP). Professor Assistente de doutor do Departamento de Educação Ciências Sociais e Políticas Públicas e dos cursos de Pós-Graduação em Educação Escolar da Unesp Campus de Araraquara. (Unesp, Araraquara (SP), Brasil). Rodovia Araraquara-Jaú, km 1, Bairro dos Machados, Caixa Postal 174, CEP.: 14.800-901, Araraquara (SP). E em Serviço Social da Unesp Campus de Franca. (Unesp, Franca, Brasil). Av. Eufrásia Monteiro Petráglia, 900, Prolongamento Jardim Dr. Antonio Petraglia, Franca (SP).CEP.: 14409-160. E-mail: <hilda_gs@yahoo.com.br>. ORC ID: <https://orcid.org/oooo0003-2877-0536>.
} 
to federal public higher education. Just as it i primordial the understanding of the history to mark the process of conformation of the agenda and conflicts of interests of the system of quotas, that took the approval of the Law n. 12,711, August 29, 2012. The study is part of a master's thesis, funded by CAPES, completed in 2017. It is concluded that research opens qualitative paths for new research, as well as contributing as a theoretical contribution to the reflection of the access to public higher education.

\section{KEYWORDS}

Quotas. College education. Affirmative actions.

Submetido em: 1/5/2018.

Aceito em: 28/5/2018.

\section{INTRODUÇÃO}

Sabe-se que as cotas são uma espécie de ação afirmativa, portanto, vamos retomar o conceito de ações afirmativas, que já é um tema de abordagem antiga e busca romper com as desigualdades históricas ou sociais. Vejamos:

As ações afirmativas representam um conjunto de ações públicas que visam o rompimento de desigualdades históricas ou sociais no acesso ao efetivo exercício de direitos, bens e serviços considerados essenciais para uma vida digna. Desigualdades essas que não conseguem ser rompidas com os mecanismos tradicionais de inclusão social, como a expansão do mercado de trabalho ou o acesso universal à educação (ROZAS, 2009, p. 20).

As ações afirmativas foram propostas há muito tempo; elas estão previstas, inclusive, na Convenção Internacional sobre a Eliminação de todas as Formas de Discriminação Racial, de 21 de dezembro de 1965:

O parágrafo $4^{\circ}$ do art. $1^{\circ}$ estipula que não serão consideradas discriminatórias 'as medidas especiais tomadas com o único objetivo de assegurar progresso adequado de certos grupos raciais e étnicos ou de indivíduos que necessitem de proteção para poderem gozar e exercitar os direitos humanos e as liberdades fundamentais em igualdade de condições' (ROZAS, 2009, p. 24).

Desse modo, as ações afirmativas buscam remediar um passado discriminatório de forma especial e temporária. A finalidade é acelerar o processo de igualdade, por isso são criadas políticas compensatórias, destinadas a grupos em vulnerabilidade, "[...] adotadas para aliviar as condições resultantes de um pretérito discriminatório, que cumprem uma finalidade pública primordial à consolidação do projeto democrático" (ROZAS, 2009, p. 20). Parafraseando Rozas (2009), é por meio das ações afirmativas que a igualdade formal passa à igualdade substancial.

A seguir, quadro sistematizado pela autora, a partir dos elementos conceituais e integrantes das ações afirmativas, pensado por Madruga (2005): 
Quadro 1: Elementos conceituais e integrantes das ações afirmativas

A compulsoriedade ou voluntariedade e a temporariedade, ou não, das medidas a serem adotadas por órgãos públicos e ou privados - as iniciativas podem advir tanto dos organismos estatais como da iniciativa privada;

A concessão de benefício ou vantagem a determinados grupos sociais - o cerne da discriminação positiva está em direcionar a execução de medidas públicas ou privadas em favor de grupamentos humanos socialmente discriminados, adotando como critério a raça, sexo, idade, religião, opção sexual, deficiência física ou psíquica, dentre outros;

A busca da igualdade de oportunidades e tratamento - o intuito principal é beneficiar determinada parcela da população, colocando-a em igualdade de condições de competitividade de atendimento com os demais segmentos sociais;

Medidas direcionadas, em especial, à área de educação, saúde e emprego

Fonte: Elaborado por Mariana Rosa Alves Ladeira a partir de Madruga (2005, p. 63-64).

A autora Rozas (2009) diz que o emprego pioneiro da expressão ação afirmativa foi feito pelo presidente norte-americano John Kennedy, na Executive Order n. 10.925 / 1961; e o objetivo desse texto normativo foi "[...] a imposição da observância de determinadas condutas antidiscriminatórias aos órgãos federais e àqueles beneficiados com projetos financiados com recursos públicos" (ROZAS, 2009, p. 20).

Utilizada em diversos países, a ação afirmativa também passou a envolver os indivíduos como prejudicados pela discriminação a que eram submetidos. Alguns documentos internacionais apresentam esse tipo de definição. Segundos os Anais do documento 'Perspectivas Internacionais em Ação Afirmativa', resultado de um encontro de pesquisadores ocorrido em agosto de 1982, no Centro de Estudos e Conferências de Bellagio, na Itália, a ação afirmativa pode ser uma preferência especial em relação a membros de um grupo definido por raça, cor, religião, língua ou sexo, com o propósito de assegurar acesso a poder, prestígio e riqueza. De acordo com a Conferência de Liderança em Direitos Civis, de 1995, esta ação engloba, além de simples extinção da prática discriminatória, qualquer medida adotada para corrigir e/ou compensar por atos discriminatórios passados ou presentes, bem como para prevenir novas ocorrências. (MOEHLECKE, 2000, p. 7-8 apud ROZAS, 2009, p. 22).

Ao observar seu histórico e conceituação, têm-se os fundamentos para as ações afirmativas, que se dividem em argumentos favoráveis e contrários em três diferentes teorias:

Quadro 2: Fundamentos para as ações afirmativas

\begin{tabular}{|c|c|c|}
\hline & Argumentos Favoráveis & Argumentos Contrários \\
\hline $\begin{array}{l}\text { Teoria da Justiça } \\
\text { Compensatória }\end{array}$ & $\begin{array}{l}\text { Ações afirmativas como reparação ou } \\
\text { ressarcimento dos danos causados } \\
\text { pelas discriminações ocorridas no } \\
\text { passado. }\end{array}$ & $\begin{array}{l}\text { Será possível impor aos brasileiros cujos } \\
\text { ascendentes nada tiveram a ver com a } \\
\text { criação e manutenção dessa forma } \\
\text { capitalista de barbárie institucionalizada, } \\
\text { a responsabilização pela reparação } \\
\text { pecuniária? }\end{array}$ \\
\hline $\begin{array}{l}\text { Teoria da Justiça } \\
\text { Distributiva }\end{array}$ & $\begin{array}{l}\text { Ações afirmativas como uma } \\
\text { redistribuição dos ônus e bônus entre } \\
\text { os membros da sociedade, com o } \\
\text { desiderato de viabilizar o acesso de } \\
\text { minorias ou grupos sociais a } \\
\text { determinadas posições. } \\
\text { Deve ser estruturado de forma que a }\end{array}$ & $\begin{array}{l}\text { Nem sempre é possível identificar, } \\
\text { dentre as diversas iniquidades sociais, } \\
\text { quais decorreriam da discriminação racial } \\
\text { e quais seriam resultantes de outros } \\
\text { fatores. }\end{array}$ \\
\hline
\end{tabular}




\begin{tabular}{|c|c|c|}
\hline & $\begin{array}{l}\text { distribuição se dê de forma justa, ou } \\
\text { seja, deve haver um sistema de } \\
\text { igualdade } \text { de oportunidades } \\
\text { equitativas, em oposição à igualdade } \\
\text { formal. }\end{array}$ & \\
\hline Teoria Mista & $\begin{array}{l}\text { As ações afirmativas legitimam-se com } \\
\text { base nos princípios de pluralismo } \\
\text { jurídico e da dignidade da pessoa } \\
\text { humana, estruturadas no paradigma do } \\
\text { Estado Democrático de Direito. }\end{array}$ & Não consta. \\
\hline
\end{tabular}

Fonte: Elaborado por Mariana Rosa Alves Ladeira a partir de Rozas (2009, p. 25-27).

As três teorias são utilizadas por diferentes autores, assim, tanto há posicionamentos que justificam as ações afirmativas, como há também críticas. A seguir, duas tabelas sistematizam esses argumentos:

Quadro 3: Principais argumentos apresentados como justificativa para as ações afirmativas

Correção dos efeitos presentes de atos discriminatórios passados: a ação afirmativa é um mecanismo corretivo que busca compensar os efeitos de atos discriminatórios praticados no passado;

Instituição de um igualitarismo justo e/ou eficiente: a ação afirmativa representa um mecanismo de redistribuição que permite a correção de desigualdades existentes entre grupos sociais. Referida redistribuição, por sua vez, diminui a pobreza e a tensão social, ampliando a prosperidade em toda a sociedade;

Prevenção de discriminação futura: a ação afirmativa diminui as possibilidades de novas ações discriminatórias;

Diversidade: a ação afirmativa é uma ferramenta que promove a diversidade.

Fonte: Elaborado por Mariana Rosa Alves Ladeira a partir de Menezes (2001, p. 16-20).

Quadro 4: Principais críticas apresentadas às ações afirmativas

Discriminação reversa: a ação afirmativa consiste em um procedimento condenável, na medida em que utiliza o mesmo critério arbitrário de diferenciação que foi usado no passado, para discriminar um determinado grupo social, embora com o fito deliberado de compensá-lo;

Acirramento da discriminação: a ação afirmativa reforça o preconceito;

Comprometimento do sistema meritocrático: a ação afirmativa ocasiona a escolha de pessoas menos qualificadas;

Concessão de benefícios para pessoas que não se encontram em situação desvantajosa: a ação afirmativa acaba por favorecer indivíduos que não necessitam de tais benefícios;

A penalização de "indivíduos inocentes": a ação afirmativa prejudica aqueles que não são pessoalmente responsáveis pelas discriminações e injustiças ocorridas no passado;

Estigmatização: a concessão de benefícios tende a estigmatizar tanto aqueles que os recebem (a tendência deles depreciarem as próprias conquistas), como aqueles que deixam de recebê-los (possibilidade deles desvalorizarem aqueles que obtiveram êxito às custas das vantagens ofertadas);

Equívocos na seleção dos critérios distintivos: em muitos casos, as desigualdades existentes decorrem, principalmente, de fatores econômicos, pelo que a utilização de outros critérios, tais como raça e gênero, apresenta uma opção injustificada.

Fonte: Elaborado por Mariana Rosa Alves Ladeira a partir de Menezes (2001, p. 16-20).

No Brasil, as desigualdades raciais ganharam maior visibilidade pública e governamental a partir do final dos anos 1990, mas, desde a década de 1980 as reivindicações do movimento negro já tinham entrado na agenda do governo do presidente Fernando Henrique Cardoso (PSDB) (1995-2002), e depois do governo de Luís Inácio Lula da Silva 
(PT) (2003-2010), e foram recebidas com receptividade (FERES JÚNIOR; DAFLON; CAMPOS, 2012).

Inclusive, Fernando Henrique Cardoso "[...] foi o primeiro presidente brasileiro a abertamente reconhecer a existência de discriminação racial no país. Sua posição em relação a políticas efetivas, no entanto, foi vaga, se não ambivalente." (FERES JÚNIOR; DAFLON; CAMPOS, 2012, p. 401).

\begin{abstract}
Em uma conferência organizada pelo governo federal em 1996, ele declarou que o Brasil "deveria procurar soluções que não sejam simples cópias ou repetições de soluções pensadas para outras situações nas quais o preconceito e a discriminação estão presentes, mas em um contexto diferente do nosso". Esse argumento foi uma referência explícita aos Estados Unidos e desde então se tornou comum entre aqueles que se opõem às ações afirmativas. (FERES JÚNIOR; DAFLON; CAMPOS, 2012, p. 401).
\end{abstract}

Lima (2010, apud FERES JÚNIOR; DAFLON; CAMPOS, 2012) diz que a análise dos documentos do período de governo FHC revela que, apesar das iniciativas voltadas à população negra, "[...] a estratégia discursiva e a política deste governo foram promover o reconhecimento sem investimentos no aspecto redistributivo" (LIMA, 2010, p. 81 apud FERES JÚNIOR; DAFLON; CAMPOS, 2012, p. 402). Foi uma política marcada pela "não ação", pois nesse momento o problema ainda não foi incorporado na agenda como prioridade.

\begin{abstract}
Em setembro de 2001, uma delegação brasileira foi a Durban, África do Sul, para participar da Conferência Mundial Contra o Racismo. O evento catalisou uma reflexão nacional sobre o racismo e o governo federal assinou então a Declaração de Durban, se comprometendo a criar políticas afirmativas que visassem a combater a discriminação racial (HTUN, 2004). Ainda em 2001, três ministérios anunciaram a criação de programas de ação afirmativa para contratação dos seus funcionários. Em maio de 2002, Cardoso lançou o Segundo Plano Nacional de Direitos Humanos, que incluía disposições para ação afirmativa sensíveis à raça, mas o congresso nunca chegou a votá-lo. Ele também criou o Programa Nacional de Ação Afirmativa, que incluía cotas para negros e mulheres como critério mandatório para contratações de servidores públicos federais e trabalhadores, servindo a empreiteiras com contratos com o governo (TACHINARDI, 2002), algo similar à Ordem da Filadélfia, de 1969, que previa medidas semelhantes nos Estados Unidos. No entanto, o programa não foi implantado (FERES JÚNIOR; DAFLON; CAMPOS, 2012, p. 402).
\end{abstract}

Foi na administração do governo Lula (PT) (2003-2011) que os esforços foram envidados para "[...] institucionalizar medidas de ação afirmativa por meio da criação de programas, leis e decretos em cuja discussão e elaboração o movimento negro desempenha um papel fundamental" (FERES JÚNIOR; DAFLON; CAMPOS, 2012, p. 403). O governo Lula também criou uma secretaria dedicada à promoção da igualdade racial, em 2003, disseminando a politização do debate a todos os níveis da sociedade, chamada Secretaria de Políticas de Promoção da Igualdade Racial (Sepir).

Ao longo dos anos seguintes, testemunha-se uma intensa negociação entre as instituições do Estado, o movimento negro, os pré-vestibulares comunitários, 


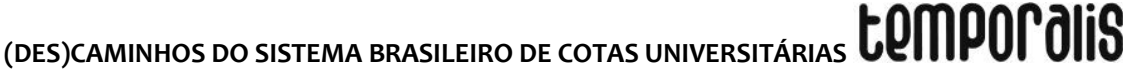

como, por exemplo, Educafro e pré-vestibular para negros e carentes, a academia, a mídia e a sociedade civil em torno da interpretação da questão racial e da melhor maneira de solucioná-la (FERES JÚNIOR; DAFLON; CAMPOS, 2012, p. 403).

O Programa Universidade para Todos (ProUni) é uma ação afirmativa brasileira, política de impacto no ensino superior privado. Nasceu em 2004, de iniciativa do então Ministro da Educação Tarso Genro (PT), que propôs o aproveitamento de 100 mil vagas ociosas nas universidades privadas, para destinar a estudantes de baixa renda. O ProUni é institucionalizado pela Lei $n^{\circ} 11.096$, de 13 de janeiro de 2005.

São contemplados pelo programa estudantes egressos do ensino médio na escola pública ou bolsistas da rede particular que comprovem ter renda familiar per capita inferior a três salários mínimos, reservadas cotas para deficientes físicos e para candidatos pretos, pardos e indígenas de acordo com sua proporção na população de cada estado, segundo o recenseamento do IBGE (FERES JÚNIOR; DAFLON; CAMPOS, 2012, p. 404).

Outra iniciativa de ação afirmativa, também destinada ao ensino superior privado, é o Fundo de Financiamento ao Estudante do Ensino Superior (FIES):

Esse programa surgiu em substituição ao antigo Creduc, passando por reformulações cujo objetivo foi torná-lo mais acessível para estudantes de classe média baixa. A demanda pela mudança veio da ONG Educafro, que arguiu a inconstitucionalidade da exigência de fiança pelo Fies, que resultava em uma exclusão do estudante pobre. O Ministério Público Federal moveu então uma ação civil pública que interditou a exigência de fiança pela Caixa Econômica Federal, culminando na criação de um programa que permite até mesmo sua conjugação com o ProUni: o bolsista parcial do ProUni pode financiar via Fies até $100 \%$ da mensalidade não coberta pelo programa. (HERINGER, 2009 apud FERES JÚNIOR; DAFLON; CAMPOS, 2012, p. 404).

No ensino superior público, além das cotas, também existe o Programa de Apoio à Planos de Reestruturação e Expansão das Universidades Federais (Reuni), instituído pelo Decreto $n^{\circ} 6.096$, de 24 de abril de 2007, que busca ampliar o acesso e a permanência na educação superior. A meta do programa, segundo o Ministério da Educação (2017) “[...] é dobrar o número de alunos nos cursos de graduação em dez anos, a partir de 2008, e permitir o ingresso de 680 mil alunos a mais nos cursos de graduação". Para isso, as ações preveem aumento de vagas, abertura ou ampliação de cursos noturnos, aumento do número de alunos por professor, a redução do custo por aluno, a flexibilização de currículos e o combate à evasão.

\section{DESENVOLVIMENTO}

\section{Ontem e hoje: retomando o contexto político social das cotas}

De acordo com Bezerra e Gurgel, até os anos 1990, a educação superior no Brasil era “[...] patrimônio reservado aos estudantes provenientes das camadas mais altas da população" (BEZERRA; GURGEL, 2011, p. 3). Os autores pontuam que houve uma expressiva expansão nos últimos anos, mas que, mesmo assim, o acesso ainda é restrito a 
uma minoria. A Pesquisa Nacional por Amostra de Domicílio (PNAD) (INSTITUTO BRASILEIRO DE GEOGRAFIA E ESTATÍSTICA, 2016, p. 45) - reafirma a questão, relatando que, em 2015 , apenas $13,5 \%$ da população de 25 anos ou mais de idade possuía ensino superior completo.

De acordo com Braga (2008), a educação superior é vital para colocar a América Latina no caminho do desenvolvimento econômico e social sustentado, cuja chave consiste, através da mobilidade social, na maior participação dos pobres e dos setores sociais excluídos na educação superior. Sustenta o Autor que a inclusão de pobres e das populações indígenas, no ensino superior, evita a perda de talentos e fornece um caminho possível para superar a pobreza (BEZERRA; GURGEL, 2011, p. 3).

Como vimos anteriormente, ação afirmativa e política de cotas não são sinônimos; Rozas (2009) destaca: “[...] esta é espécie da qual aquela é gênero" (ROZAS, 2009, p. 23). As ações afirmativas são abrangentes, estando relacionadas à correção de desigualdades. Elas estão presentes na esfera privada e na esfera pública, alguns exemplos são:

[...] a concessão de bolsas de estudos e cursos pré-vestibulares para alunos negros e hipossuficientes, a implementação de programas de estágio e capacitação profissional aos jovens, a ampliação do financiamento estudantil e a contratação e a promoção de trabalhadores, levando em conta, além da qualificação profissional, o viés étnico-racial (ROZAS, 2009, p. 23).

Logo, se "[...] a igualdade perante à lei não se realiza completamente se todas as pessoas não tiverem efetiva condição de exercê-la [...]" (ROZAS, 2009, p. 22), então é preciso que o Estado tome partido e implemente políticas a fim de sanar essas diferenças.

Ora, as desigualdades no Brasil têm raízes tão profundas que rompê-las não
parece depender somente do desenvolvimento econômico. São necessárias
políticas de distribuição de renda sob pena do desenvolvimento econômico
isolado gerar ainda maior desigualdade social e racial. Na tentativa de fixar um
critério justo para a distribuição de recursos, John Rawls estabelece o 'princípio
da diferença', segundo o qual as desigualdades sociais e econômicas devem ser
arranjadas de forma a que sejam benéficas aos menos favorecidos. Assim, de
acordo com este princípio, será justa uma sociedade se organizada de maneira
que as contingências naturais ou sociais trabalhem a favor dos menos
favorecidos. (ROZAS, 2009, p. 22).

Portanto, é preciso fazer desigualações, por isso as cotas foram implementadas. Bourdieu enfatiza que a escola, por vezes, "[...] consagra as desigualdades reais, [...] contribui para perpetuar as desigualdades, [...] as legitima" (BOURDIEU, 2014, p. 65). Ela "[...] favorece os mais favorecidos" (BOURDIEU, 2014, p. 62). E isso é justamente o que não deveria acontecer, pois somente a escola pode reduzir essas desigualdades, já que sua função é transmitir atitudes e aptidões por meio do aprendizado, ou seja, incitar a prática cultural (BOURDIEU, 2014).

Jessé Souza ressalta que a falta de consciência das pessoas é que traz ainda mais contradições no contexto de desigualdades (SOUZA, 2003). É preciso dar visibilidade ao tema, é preciso falar de cotas como um modelo paliativo, mas necessário. O sistema de 
cotas brasileiro trata desigual os desiguais, em meio às diferenças latentes de ensino público e privado. Jessé também diz que a invisibilidade da desigualdade vai além de uma questão de gerência, é preciso uma mudança, uma transformação que faça diferenciações de acordo com as peculiaridades de cada grupo social, sem inferiorizar nenhum cidadão (SOUZA, 2009).

Ora, mas qual foi então o percurso para que as universidades começassem a destinar vagas para cotistas? Ao observar a história do Brasil, no que tange à educação superior, percebe-se que:

[...] a política educacional do pós-guerra, resultante do pacto populista, levava o Estado a ampliar as oportunidades de escolarização para as camadas médias e para o proletariado. No ensino de segundo grau, a expansão dos ginásios públicos esvaziava as escolas privadas, confessionais e não. Com a queda dos lucros em função da diminuição do número de anos e do aumento dos salários dos professores que se organizavam em sindicatos, o capital deslocou-se para o ensino superior, onde encontrou condições propícias para a rápida multiplicação (CUNHA, 1989, p. 37).

Cunha (1989) ressalta que, nos anos 50 e 60, essa demanda se expressou nas grandes cidades; já nos anos 70 e 80, ela se espalhou pelas cidades médias e pequenas. Esse fato acarretou mudanças no perfil dos estudantes, recebendo setores de todas as classes sociais e também mulheres, uma vez que os cursos eram tipicamente masculinos, e tal cenário se alterou desde então.

Em meados de 1973/1974, o fenômeno chamado de milagre econômico, bem como o cenário internacional, levou as classes trabalhadoras e camadas médias da sociedade que integravam o alunado das instituições privadas - a sentirem os efeitos da crise diretamente nos salários, na inflação, no desemprego; acarretando o abandono dos cursos superiores, assim como a diminuição do número de candidatos nos vestibulares.

Diante da previsível insolvência de numerosos estabelecimentos privados de ensino, o governo federal criou um programa pelo qual as organizações bancárias foram autorizadas a utilizar parte dos recursos que deveriam ser compulsoriamente depositados no Banco Central para financiar o pagamento das taxas cobradas naquelas instituições, para posterior reembolso pelos estudantes, de modo a se manter um fundo rotativo (CUNHA, 1989, p. 43).

Ou seja, foram feitos investimentos no setor privado. Ficaram visíveis os conflitos de interesse - o mercado ditando as regras - e as fragilidades do sistema público de educação, atingindo diretamente as classes menos favorecidas, já que o ensino público não recebia os investimentos necessários para uma educação de qualidade e abrangência que atendesse a todos. Pode-se inferir que ainda hoje o cenário permanece muito semelhante.

No período de 1968 a 1988, no Brasil, houve uma maior preocupação com a educação superior, com vistas a reorganizar a universidade, mas com uma estrutura tecnicista, departamental, e que censurava a criticidade no meio acadêmico. Em contexto de 
redemocratização, a década de 1980 também culminou em avanços, como a Constituição da República Federativa do Brasil de 1988, dando maior autonomia às universidades, garantindo a indissociabilidade entre ensino, pesquisa e extensão.

Na década de 1990, a economia brasileira sofreu fortes influências do capital financeiro transnacional, o qual contribuiu para o fortalecimento da lógica neoliberal; assim, cresceu a mercantilização da educação, preparando profissionais para o mercado de trabalho. "O conhecimento, a ciência e as próprias instituições de ensino acabam por se tornar peças na engrenagem do sistema" (BENINCÁ, 2011, p. 38).

Em meio a esse cenário, nos anos 2000 surgiram propostas de democratização da universidade pública na busca pela ampliação do acesso, em especial, para a classe menos favorecida brasileira, que, em sua maioria, tem menos oportunidades de acesso a uma educação básica de qualidade, dando-lhes aporte para o ingresso em uma universidade pública.

A Lei n. 12.711 de 29 de agosto de 2012 (BRASIL, 2012C) é um exemplo do desdobramento das propostas supracitadas. É por isso que o Sistema de Cotas deve ser entendido com uma medida paliativa, mas também como um direito social, pois a esfera da educação pode ter a tônica do seu desenvolvimento vinculada ao capital, mas não é impossível transformá-la, refazê-la; ao contrário, é uma possibilidade real que se assenta em colocar a educação "[...] a serviço dos excluídos [...]", como diz Pedro Demo (1997, p. 52).

O histórico das ações afirmativas no Ensino Superior mostra que as primeiras iniciativas de cotas no Brasil ocorreram nos anos 2000. A discussão não surgiu em 2000, mas sim o aprofundamento e a concretização da primeira implementação de um sistema de cotas. Em 1996, por exemplo, o Programa Nacional dos Direitos Humanos (PNDH) já sinalizava a importância de medidas afirmativas no âmbito da educação:

[...] desenvolver ações afirmativas para o acesso dos autodeclarados negros aos cursos profissionalizantes, à universidade e às áreas de tecnologia de ponta [...] formular políticas compensatórias que possam promover social e economicamente a comunidade negra [...] e apoiar as ações da iniciativa privada que realizem discriminação positiva (ROZAS, 2009, p 24).

No ano de 2002, a questão toma mais amplitude:

A Medida Provisória n. ${ }^{\circ}$ 63, de 26 de agosto de 2002, convertida na Lei n. ${ }^{\circ} 10.558$, de 13 de novembro de 2002, cria o Programa Diversidade na Universidade Brasileira. Nesta Lei são delineadas as características das instituições de ensino que poderão receber recursos da União, originários deste programa. Na Exposição de Motivos n. ${ }^{\circ}$ 084, de 16 de agosto de 2002, do Ministro de Estado da Educação, que acompanhou o projeto de Medida Provisória para criação do Programa de Diversidade na Universidade, informava-se que ela tinha o objetivo de incentivar projetos inovadores que promovessem o acesso ao ensino superior de grupos socialmente desfavorecidos. Citava que a implementação do programa permitiria fortalecer os mecanismos de diálogo entre as diversas instâncias e atores do setor público, o setor acadêmico e a sociedade civil, como uma prática possível de formulação de políticas públicas e de controle social. 


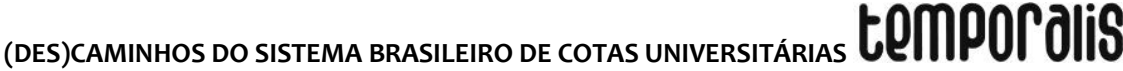

Expunha ainda, que o programa era consistente com a estratégia do país, já que enfocava a redução das desigualdades sociais mediante a atenção à população excluída e contribuía para a redução da pobreza (BRAGA, 2014, p. 22).

A instituição pioneira, que deu o passo inicial para a democratização do acesso à educação superior - mesmo que o ensino universitário ainda esteja longe de ter seu acesso pleno e universal —, foi a Universidade Estadual do Rio Janeiro (UERJ), em 2003, ao implantar a primeira política de cotas no Brasil. Foi a Lei Estadual n. 4.151/2003, que regulamentou essa iniciativa, ao estabelecer cotas para estudantes carentes do Rio de Janeiro, no ensino superior estadual, com vistas a reduzir as desigualdades étnicas, sociais e econômicas. A distribuição do percentual de vagas se subdividia em: $20 \%$ para estudantes oriundos de rede pública de ensino; $20 \%$ para negros; e $5 \%$ para pessoas com deficiência, nos termos da legislação em vigor e integrantes de minorias étnicas. Além do fator renda bruta média familiar, em 2004: 300,00 (trezentos reais); 2005 e 2006: 520,00 (quinhentos e vinte reais); 2007: 630,00 (seiscentos e trinta reais); e a cada ano reajustados de acordo com o salário mínimo.

Segundo definição do Grupo de Estudos Multidisciplinar da Ação Afirmativa
(Gemaa), do Instituto de Estudo Sociais e Políticos da UERJ, ações afirmativas
são políticas que destinam recursos para beneficiar pessoas de grupos
discriminados e vitimados pela exclusão socioeconômica no passado, ou no
presente. Essas ações incluem medidas que têm por objetivo combater
discriminações étnicas, raciais, religiosas, de gênero, ou de casta, aumentando,
assim, a participação de minorias no processo político, no acesso à educação,
saúde, emprego, bens materiais, redes de proteção social, ou no
reconhecimento cultural (EM 2003, UERJ..., 2013, não paginado).

A primeira universidade federal a adotar uma política de cotas foi a Universidade de Brasília (UnB), em 2004, destinando $20 \%$ das vagas a estudantes autodeclarados negros. Além de ser a "[...] primeira universidade pública a aprovar cotas a partir de uma decisão baseada na autonomia do seu máximo Conselho Acadêmico" (UNIVERSIDADE DE BRASÍLIA, 2013, p. 36). Isso porque a proposta já havia sido apresentada em 1999 (NASCIMENTO A. et al., 2008).

O sistema de cotas para negros na UnB teve início no vestibular do segundo semestre de 2004, sendo o período limite para revisão da política o primeiro semestre de 2014. Tal sistema foi colocado em prática após muito debate e discussão por parte da comunidade acadêmica. A ideia era instaurar, no espaço acadêmico, um mecanismo reparador das perdas infringidas à população negra brasileira (UNIVERSIDADE DE BRASÍLIA, 2013, p. 3).

No relatório da UnB de 2013, desde a implantação das cotas na referida universidade, foram homologados cerca de 34.679 candidatos no sistema de cotas para negros até o ano de 2013 , o correspondente a $53,6 \%$ do total de inscritos no sistema (UNIVERSIDADE DE BRASÍLIA, 2013). Ressalta-se que a universidade aponta conclusões positivas: “[...] com as cotas, a UnB escolheu o caminho certo e o debate nacional que se instalou desde então confirmou esse acerto." (UNIVERSIDADE DE BRASíLIA, 2013, p. 36). 


\begin{abstract}
Do ponto de vista acadêmico, [...] o rendimento dos estudantes formados, em todas as áreas do conhecimento, não varia muito entre cotistas e aqueles que ingressaram pelo sistema universal. Além disso, [...] a expressiva quantidade de estudantes negros que não teriam ingressado na UnB se não houvesse a possibilidade de concorrência pelo referido sistema de cotas, o que corrobora o argumento inicial acerca da necessidade de se manter essa política pública de inclusão social (UNIVERSIDADE DE BRASÍLIA, 2013, p. 36).
\end{abstract}

Em 2004, houve a iniciativa do Projeto de Lei n. 3.627 (PODER EXECUTIVO, 2004), que instituiu o Sistema Especial de Reserva de Vagas para estudantes egressos de escolas públicas, em especial negros e indígenas, nas instituições públicas federais de educação superior. Foi um projeto elaborado pelo Poder Executivo (Tarso Genro - PT), e foi um dos primeiros projetos que instituía as cotas não apenas raciais, mas também sociais. $E$, em 2008, houve o Projeto de Lei n. 3.913, da senadora Ideli Salvatti (PT), que dispunha sobre - sistema de reserva de vagas para estudantes egressos de escolas públicas nas instituições federais de educação superior, profissional e tecnológica (SALVATTI, 2008).

Em novembro de 2008 foi apresentado o Projeto de Lei da Câmara n. 180 (LOBÃO, 2008), de autoria da Deputada Abdenice Lobão (PSD-MA); relatoria da Senadora Serys Slhessarenko (PRB), que dispõe sobre o ingresso nas universidades federais e estaduais e nas instituições federais de ensino técnico de nível médio. No dia 18 de dezembro do mesmo ano, o projeto foi para a Comissão de Constituição, Justiça e Cidadania, em que ocorreu a primeira audiência pública com representantes do Ministério da Educação, do Educafro, da Secretaria de Educação Continuada, Alfabetização e Diversidade, do Movimento dos Sem Universidades, do Movimento Negro Socialista, do Movimento Nação Mestiça, do grupo Direitos Humanos e Igualdade Étnica, dentre outros.

Em março de 2009, foi realizada a segunda audiência pública; em abril, a terceira. O Projeto de Lei da Câmara n. 129, de 2009 (MATTOS et al., 2009), passa a tramitar em conjunto com o PL 180, que se encontra apensado aos PL do Senado n. 971/2015 (NASCIMENTO, 2015); 344/2008 (PERILLO JÚNIOR, 2008) e 479/2008 (DIAS, 2008), porém os dois últimos ficam prejudicados na aprovação final. No dia 07 de agosto de 2012, o PL 180 vai ao Senado para aprovação, e, apesar do voto contrário do Senador Aloysio Nunes Ferreira (PSDB), o Projeto é aprovado e segue para a sanção presidencial. Ainda em agosto, o PL é transformado em norma jurídica com veto parcial.

A Presidente da República Dilma Rousseff então sanciona a Lei n. 12.711/2012 (BRASIL, 2012C), que estabelece cotas de no mínimo 50\% das vagas de instituições públicas federais para estudantes que cursaram o ensino médio integralmente em escolas públicas. Dentre essas vagas, 50\% são reservadas a estudantes oriundos de famílias com renda igual ou inferior a um salário e meio per capita. Também são reservadas vagas aos candidatos autodeclarados pretos, pardos e indígenas, em proporção igual à sua distribuição nas unidades da Federação em que são localizadas as instituições federais de ensino superior, e de acordo com o último censo do Instituto Brasileiro de Geografia e Estatística (IBGE).

A Lei é regulamentada pelo Decreto n. 7.824, de 11 de outubro de 2012 (BRASIL, 2012C), e pela Portaria Normativa n. 18, de 11 de outubro de 2012, que dispõe sobre a 


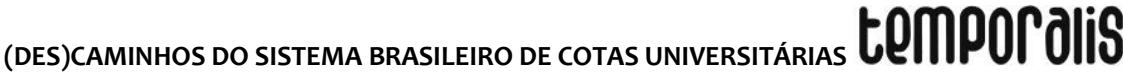

implementação das reservas de vagas em instituições federais de ensino. Esses são os documentos que respaldam a atual política de cotas universitárias.

\title{
A conformação da agenda e os grupos de interesses: (des)caminhos da Política de Cotas Universitárias
}

Durante a conformação da agenda, percebem-se conflitos de interesses, como os embates entre os que são a favor das cotas e os que não são. Portanto, é válido retomar o conceito de agenda, proposto por Serafim e Dias (2012), já que vamos discutir a conformação da agenda para a implementação das cotas:

\begin{abstract}
A agenda pode ser entendida como o 'espaço problemático' de uma sociedade. Um determinado tema é incorporado à agenda quando é identificado como problema passível de se converter em política pública. Esse processo não deve ser entendido como estritamente técnico: a identificação do problema e a construção da agenda envolvem valores e interesses, estão condicionadas a elementos ideológicos e a projetos políticos e refletem as relações de poder entre os atores sociais envolvidos. As políticas públicas, por sua vez, seriam posicionamentos possíveis em relação a essa agenda, dadas as possibilidades teóricas, políticas e materiais apresentadas aos atores que participam do jogo político (SERAFIM; DIAS, 2012, p. 123).
\end{abstract}

Nesse espaço problemático, os Anti-Racistas, em 28 de abril de 2007, entregaram ao Supremo Tribunal Federal o Manifesto intitulado 113 Cidadãos Anti-Racistas Contra as Cotas Raciais, em apoio à Ação de Inconstitucionalidade (ADI) impetrada pela Confederação Nacional dos Estabelecimentos de Ensino (Confenen) e pelo Partido Democratas.

O teor do manifesto amplia pontos já tratados ligeiramente em um Manifesto anterior, intitulado 'Todos são Iguais na República Democrática', entregue ao Congresso Nacional no dia 30 de maio de 2006 pelo mesmo grupo de pessoas, naquela vez insurgindo- se contra o PL da Lei de Cotas e contra o Estatuto da Igualdade Racial (NASCIMENTO et al., 2008, p. 13).

Esses 113 cidadãos se apresentam como "[...] intelectuais da sociedade civil, sindicalistas, empresários e ativistas dos movimentos negros e outros movimentos sociais [...]" (NASCIMENTO et al., 2008, p. 14), são 80 professores universitários e pesquisadores e, desses 80 , apenas 1 é negro. Eles, representando uma elite acadêmica branca, solicitam "[...] o retorno ao estado de exclusão do racismo institucional que imperava indiscriminadamente nas universidades brasileiras, e a manutenção dos índices de presença da população negra que existia há 10 anos atrás" (NASCIMENTO et al., 2008, p. 14).

[...] a existência de movimentos anti-racistas e de leis de repressão da discriminação racial não se baseia no reconhecimento da existência das raças, mas na necessidade de combater as discriminações geradas por esse pensamento que se pretende cientifico. Enfim, no nível político, eles cometem uma tríplice impostura: i) dizem que no Brasil apenas existe uma questão social, ou seja, ignoram a correlação sistemática que todos os estudos estatísticos indicam entre linhas de cor e curvas da pobreza, bem como que as cotas promovem também os outros segmentos de população discriminados pelo atual 


\begin{abstract}
sistema de acesso ao ensino superior; ii) afirmam o mérito como único critério republicano, o que é duplamente falso: porque uma sociedade democrática sabe que o mérito deve ser um ponto de chegada e não um ponto de partida e é exatamente nessa medida que a democracia será sempre mais estável e mais próspera; porque toda política de desenvolvimento do conhecimento implica em sistemas de cotas (bolsas!) justamente destinadas a promover a excelência pelo subsídio a determinados segmentos de população; iii) reivindicam o pacto republicano, mas ignoram que tal pacto não é algo dado, mas um algo que precisamos construir para avançarmos nas conquistas democráticas. (NASCIMENTO, 2008, p. 13).
\end{abstract}

Nesse cenário, encontra-se também a Arguição de Descumprimento de Preceito Fundamental 186, de agosto de 2009, ajuizada pelos Democratas (DEM), partido político com representação no Congresso Nacional, em face da instituição das cotas raciais na Universidade de Brasília (UnB). A ADPF $186^{1}$ defende que a UnB, ao instituir as cotas raciais, instituiu um verdadeiro Tribunal Racial.

[...] a presente arguição não visa a questionar a constitucionalidade de ações afirmativas como políticas necessárias para a inclusão de minorias, ou mesmo a adoção do modelo de Estado Social pelo Brasil e a existência de racismo, preconceito e discriminação na sociedade brasileira. Acentua, dessa forma, que a ação impugna, especificamente, a adoção de políticas afirmativas 'racialistas', nos moldes da adotada pela UnB, que entende inadequada para as especificidades brasileiras (BRASIL, 2012, p. 172).

A ADPF 186 afirma que existe uma violação de princípios fundamentais, como a igualdade e a dignidade humana, na medida em que o sistema de cotas raciais da UnB ressuscita a crença de que é possível identificar a que raça pertence uma pessoa (BRASIL, 2012). Além disso, no documento apresentado, sustenta-se a ideia de que a pobreza no Brasil tem todas as cores, dentre outros argumentos.

Diante da ADPF, o Presidente do Conselho de Ensino Pesquisa e Extensão da Universidade de Brasília prestou informações, dentre elas, a de que "[...] 'não é possível ignorar, face à análise de abundantes dados estatísticos, que cidadãos brasileiros de cor negra partem, em sua imensa maioria, de condições socioeconômicas muito desfavoráveis comparativamente aos de cor branca'." (BRASIL, 2012, p. 175). Assim como, depois de 10 vestibulares realizados, não era cabível a concessão da medida liminar requerida.

Em março de 2010, aconteceu a audiência pública para julgar o caso e, em 25 de abril de 2012, a ADPF 186 foi julgada improcedente. O Relator Ricardo Lewandowski, Ministro do Supremo Tribunal Federal desde março de 2006, pontuou que "[...] as políticas de ação afirmativa adotadas pela Universidade de Brasília (i) têm como objetivo estabelecer um ambiente acadêmico plural e diversificado, superando distorções sociais historicamente consolidadas." (BRASIL, 2012, p. 92).

\footnotetext{
${ }^{1}$ Medida Cautelar em Arguição de Descumprimento de Preceito Fundamental 186 - N. Prot. 2009/90369 Origem: Distrito Federal - Relator Min. Ricardo Lewandowski - Prot. 20 jul. 2009 - Inteiro teor do Acordão: Publ. DJE - 26 abr. 2012.
} 


\section{De acordo com ADI 3330²:}

5. Não há outro modo de concretizar o valor constitucional da igualdade senão pelo decidido combate aos fatores reais de desigualdade. O desvalor da desigualdade a proceder e justificar a imposição do valor da igualdade. A imperiosa luta contra as relações desigualitárias muito raro se dá pela via do descenso ou do rebaixamento puro e simples dos sujeitos favorecidos. Geralmente se verifica é pela ascensão das pessoas até então sob a hegemonia de outras. Que para tal viagem de verticalidade são compensadas com esse ou aquele fator de supremacia formal. Não é toda superioridade juridicamente conferida que implica negação ao princípio da igualdade. (BRASIL, 2012, p. 2).

A ainda ressalta:

6. O típico da lei é fazer distinções. Diferenciações. Desigualações. E fazer desigualações para contrabater renitentes desigualações. A lei existe para, diante dessa ou daquela desigualação que se revele densamente perturbadora da harmonia ou do equilíbrio social, impor uma outra desigualação compensatória. A lei como instrumento de reequilíbrio social. (BRASIL, 2012, p. 2).

Diante do exposto, a UnB continua com sua ação afirmativa voltada para a questão racial.

Como outro exemplo de conflito, a referida universidade (UnB) considera a Lei n. 12.711 como um retrocesso, quando, no documento publicado em 2013, sobre a Análise do sistema de Cotas para negros da Universidade de Brasília, assinala que:

Sobre a Lei Federal $n^{\circ}$. 12.711, conhecida como lei de Cotas, que começa a ser implementada desde o primeiro semestre de 2013, deve-se considerar que ela significa um retrocesso enquanto política de inclusão étnica e racial quando comparada com o sistema de cotas específico da UnB que, por sua vez, é amplamente reconhecido como $O$ mais avançado nacionalmente. (UNIVERSIDADE DE BRASÍLIA, 2013, p. 37).

Diz também que:

A lei 12.711 promoverá um crescimento da igualdade racial e de classe na base da pirâmide social e permitirá a continuidade e mesmo o crescimento de uma intensa desigualdade racial e social no topo da pirâmide de renda, prestígio e poder. Para a classe média negra restarão duas alternativas, difíceis de avaliar entre si, porém tão dramáticas quanto competir com a elite branca concentrada nas escolas privadas, ou competirá exclusivamente entre si no interior das escolas públicas pelas cotas nas instituições federais públicas ou se dirigirá para as faculdades privadas, onde a concorrência com os brancos poderá ser menos desigual. Nesta segunda alternativa, a família negra que acaba de ascender à classe média terá que assumir mais um ônus financeiro, porque não teve acesso a uma concorrência universal com os brancos (pobres ou ricos, de escola pública ou de escola privada) devido às limitações a ela imposta pela lei de Cotas. (UNIVERSIDADE DE BRASÍLIA, 2013, p. 39).

\footnotetext{
${ }^{2}$ Ação Direta de Inconstitucionalidade 3.330 - Origem: Distrito Federal - Relator: Min. Ayres Britto Distribuído: 21 out. 2004 - Inteiro teor do Acordão: Publ. DJE - 20 mar. 2013.
} 
Sobre esse documento, a UnB ironiza ao dizer que, com um teto de $50 \%$ de cotas de escola pública, não faz sentido chamar os outros 50\% de ampla concorrência, pois serão, na prática, cotas para escola privada (UNIVERSIDADE DE BRASÍLIA, 2013). E, nesse cenário de diferentes conexões de interesses, até mesmo os atores favoráveis ao sistema de cotas ainda divergem em sua aplicabilidade e público destinado.

Porém, pode-se inferir que a demanda por cotas é latente e que, mesmo alguns sendo contra as cotas raciais, outros a favor, outros ainda acreditando que as cotas devem ser só para alunos egressos de escolas públicas, o que importa é que as minorias ingressem no ensino superior público. A atual Lei n. 12.711, que será abordada na seção seguinte, expressa o pensamento de muitos que lutam pelas cotas; hoje, elas abrangem negros, indígenas, pobres e alunos de escola pública. Essa demanda mencionada pela lei:

[...] insere-se na busca da justiça social em uma sociedade que historicamente se mostra racista, sexista, homofóbica e excludente. As cotas e o Prouni significam uma mudança e um compromisso ético do Estado brasileiro na superação de um histórico de exclusão que atinge de forma particular negros e pobres. [...] Não se trata de leis raciais, como dizem os 113 anti-cotas, mas um posicionamento do Estado brasileiro coerente com os acordos internacionais de superação do racismo, de luta pelos direitos humanos dos quais o país é signatário. (NASCIMENTO, 2008, p. 2).

É com a difusão das cotas e de todas as ações afirmativas que se alcança a verdadeira igualdade, aquela que reconhece as diferenças e trata de modo desigual os desiguais. A lei de cotas é fruto de uma luta histórica, de muita mobilização social que estimulou os debates nos ambientes políticos e acadêmicos em todos os cantos do país.

\begin{abstract}
A colocação das cotas nas pautas de votações das Universidades brasileiras implicou mobilização, pressão, articulação e produção intelectual de ideias, argumentos, modelos e propostas de como promover a igualdade étnica e racial no ensino superior, em uma intensidade sem paralelo em nenhuma década passada da história do Brasil. (NASCIMENTO, 2008, p. 4).
\end{abstract}

No atual momento, as universidades públicas, principalmente as federais, que sempre foram fechadas à participação da sociedade "[...] foram e estão interpeladas e levadas a dialogar, de um modo franco e criativo, com as comunidades negras e indígenas, em uma intensidade e horizontalidade raras no Brasil" (NASCIMENTO, 2008, p. 11).

Adiante, a seção sobre a Lei n. 12.711/2012 explana sobre a garantia de 50\% das vagas das universidades federais para cotistas.

\title{
A Lei n. 12.711, de 29 de agosto de 2012: a garantia de 50\% das vagas das Universidades Federais para cotistas
}

Após contextualizar o Sistema de Cotas Brasileiro, o objetivo é apresentar o que está proposto nas legislações atinentes ao tema. Assim, a Lei n. 12.711, de 29 de agosto de 2012, dispõe sobre o ingresso nas universidades federais e nas instituições federais de ensino técnico de nível médio e dá outras providências. Logo no Artigo $1^{\circ}$, a Lei prevê que: 
Art. $1^{\circ}$ As instituições federais de educação superior vinculadas ao Ministério da Educação reservarão, em cada concurso seletivo para ingresso nos cursos de graduação, por curso e turno, no mínimo 50\% (cinquenta por cento) de suas vagas para estudantes que tenham cursado integralmente o ensino médio em escolas públicas.

Parágrafo único: No preenchimento das vagas de que trata o caput deste artigo, $50 \%$ (cinquenta por cento) deverão ser reservados aos estudantes oriundos de famílias com renda igual ou inferior a 1,5 salário-mínimo (um salário-mínimo e meio) per capita (BRASIL, 2012c, não paginado).

O destaque da Lei é a destinação de $50 \%$ das vagas da universidade para alunos de escolas públicas. O Artigo $3^{\circ}$, porém, prevê que, dentre essas vagas, serão reservadas também a autodeclarados pretos, pardos e indígenas, em proporção no mínimo igual à de pretos, pardos e indígenas na população da unidade da federação onde está instalada a instituição, segundo o último censo do Instituto Brasileiro de Geografia e Estatística (IBGE).

Caso essas vagas não sejam preenchidas, as remanescentes deverão ser completadas por estudantes que tenham cursado o ensino médio em escolas públicas.

É válido lembrar que a exigência é que, se a instituição federal é de nível médio técnico, os alunos devem ter cursado o ensino fundamental integral em escola pública. E se a instituição é de nível superior, os alunos devem ter cursado o ensino médio integral em escola pública.

Os Órgãos da Presidência da República responsáveis pelo acompanhamento e avaliação do programa são o Ministério da Educação e a Secretaria Especial de Políticas de Promoção da Igualdade Racial; considerando também o parecer da Fundação Nacional do Índio (Funai) (Art $6^{\circ}$ - Lei n. 12.711/2012). A revisão do programa especial para o acesso de estudantes pretos, pardos e indígenas, bem como dos alunos que cursaram o ensino médio integral em escolas públicas, será promovida pelo Poder Executivo, no prazo de dez anos, a contar da publicação da Lei n. 12.711/2012 (Art. $7^{\circ}$ ).

Conforme mencionado anteriormente, as instituições tiveram um prazo para a implementação total da lei de reserva de vagas, que se encerrou em 16 de agosto de 2016, após 4 (quatro) anos a partir da data de sua publicação. Devendo implementar, no mínimo, 25\% (vinte e cinco por cento) a cada ano.

O Decreto n. 7.824, de 11 de outubro de 2012, é o que regulamenta a Lei n. 12.711/2012. Em seu texto, prevê, no Art. $1^{\circ}$, Parágrafo Único, que

[...] os resultados obtidos pelos estudantes no Exame Nacional do Ensino Médio (ENEM) poderão ser utilizados como critério de seleção para o ingresso nas instituições federais vinculadas ao Ministério da Educação que ofertam vagas de educação superior (BRASIL, 2012b, não paginado). 
Em relação à reserva de vagas, o Decreto n. 7.824, esclarece, em seu Art. $2^{\circ}$, que devem ser implementadas, no mínimo, 50\% (cinquenta por cento) de suas vagas para alunos de escolas públicas, observadas as condições:

\begin{abstract}
I - no mínimo cinquenta por cento das vagas de que trata o caput serão reservadas a estudantes com renda familiar bruta igual ou inferior a um inteiro e cinco décimos salário-mínimo per capita; e

II - proporção de vagas no mínimo igual à de pretos, pardos e indígenas na população da unidade da Federação do local de oferta de vagas da instituição, segundo o último Censo Demográfico divulgado pelo Instituto Brasileiro de Geografia e Estatística - IBGE, que será reservada, por curso e turno, aos autodeclarados pretos, pardos e indígenas.

Parágrafo único. Para os fins deste Decreto, consideram-se escolas públicas as instituições de ensino de que trata o inciso I do caput do art. 19 da Lei $n^{\circ}$ 9.394, de 20 de dezembro de 1996 (BRASIL, 2012b, não paginado).
\end{abstract}

Para concorrer a essas vagas, as exigências são: ter cursado o ensino médio integral em escolas públicas em cursos regulares ou na modalidade Educação de Jovens e Adultos (EJA); ou ter obtido a certificação de conclusão do ensino médio por meio do resultado do ENEM, ou de exame nacional/estadual de certificação de competências de jovens e adultos.

A legislação é clara: estudantes que, em algum momento, cursaram parte do ensino médio em escolas particulares não poderão concorrer às vagas do Programa. É permitido, sem prejuízo do disposto no Decreto n. 7.824, que as instituições federais de educação possam, "[...] por meio de políticas específicas de ações afirmativas, instituir reservas de vagas suplementares ou de outra modalidade" (BRASIL, 2012b, não paginado, Art. $5^{\circ} \S 3^{\circ}$ ).

O Comitê de Acompanhamento e Avaliação, citado na Lei n. 12.711/2012, que objetiva acompanhar e avaliar o disposto na legislação, é composto por: dois representantes do Ministério da Educação, dois da Secretaria de Políticas de Promoção da Igualdade Racial da Presidência da República, e um da Fundação Nacional do Índio. Esses membros são indicados por titulares dos órgãos e entidades que representam e designados em ato conjunto; e a presidência do Comitê caberá a um dos representantes do Ministério da Educação, indicado por seu titular. A participação no comitê não é remunerada, mas considerada prestação de serviço público relevante (BRASIL, 2012b, não paginado, Art. $\left.6^{\circ}\right)$

O Art. $7^{\circ}$ (Decreto n. 7.824), versa que o Comitê é responsável por encaminhar um relatório anual de "[...] avaliação da implementação das reservas de vagas de que trata este Decreto" (BRASIL, 2012b, não paginado, Art. $7^{\circ}$ ).

As demais disposições, como a forma de apuração e comprovação da renda familiar bruta, e as fórmulas para cálculo, estão na Portaria Normativa n. 18, de 11 de outubro de 2012, que será tratada a seguir. 
A Portaria Normativa n. 18, de 11 de outubro de 2012 (BRASIL, 2012C), é a responsável por dispor sobre a implementação da reserva de vagas previstas na Lei n. 12.711/2012 e no Decreto n. 7.824/2012. Para tanto, considera, em seu Art. $2^{\circ}$ :

I - concurso seletivo, o procedimento por meio do qual se selecionam os estudantes para ingresso no ensino médio ou superior, excluídas as transferências e os processos seletivos destinados a portadores de diploma de curso superior;

II - escola pública, a instituição de ensino criada ou incorporada, mantida e administrada pelo Poder Público, nos termos do inciso l, do art. 19, da Lei $\mathrm{n}^{\circ}$ 9.394, de 20 de dezembro de 1996;

III - família, a unidade nuclear composta por uma ou mais pessoas, eventualmente ampliada por outras pessoas que contribuam para o rendimento ou tenham suas despesas atendidas por aquela unidade familiar, todas moradoras em um mesmo domicílio;

IV - morador, a pessoa que tem o domicílio como local habitual de residência e nele reside na data de inscrição do estudante no concurso seletivo da instituição federal de ensino;

$V$ - renda familiar bruta mensal, a soma dos rendimentos brutos auferidos por todas as pessoas da família, calculada na forma do disposto nesta Portaria.

$\mathrm{VI}$ - renda familiar bruta mensal per capita, a razão entre a renda familiar bruta mensal e o total de pessoas da família, calculada na forma do art. 70 desta Portaria (BRASIL, 2012C, não paginado).

A portaria corrobora o Decreto n. 7.824 ao esclarecer sobre as modalidades de reserva de vagas: o mínimo de $50 \%$ dessas vagas para estudantes de escolas públicas; as reservadas para alunos com renda inferior a um salário-mínimo e meio per capita; e as reservadas aos autodeclarados pretos, pardos e indígenas, de acordo com a Unidade da Federação. Também reafirma sobre as condições para concorrer às vagas, como por exemplo, não ter, em nenhum momento, cursado parte do ensino médio em escolas particulares.

Em relação à condição de renda, esclarece o procedimento a ser adotado para cálculo da percepção de renda familiar bruta mensal igual ou inferior a um salário-mínimo e meio per capita. São eles:
Art. $7^{\circ}[\ldots]$
I - calcula-se a soma dos rendimentos brutos auferidos por todas as pessoas da família a que pertence o estudante, levando-se em conta, no mínimo, os três meses anteriores à data de inscrição do estudante no concurso seletivo da instituição federal de ensino;
II - calcula-se a média mensal dos rendimentos brutos apurados após a aplicação do disposto no inciso I do caput; e
III - divide-se o valor apurado após a aplicação do disposto no inciso II do caput pelo número de pessoas da família do estudante (BRASIL, 2012c, não paginado).

Nesse cálculo, são computados rendimentos regulares ou eventuais de todos os membros do grupo familiar, inclusive arrendamento de bens, e locações (Art. $7^{\circ} \S 1^{\circ}$ ). São excluídos os rendimentos referentes a auxílios de alimentação e transporte, diárias e reembolsos de despesas, adiantamentos e antecipações, dentre outros (Art. $7^{\circ} \S 2^{\circ}$ ). Também são excluídos do cálculo os rendimentos no âmbito do Programa de Erradicação 
do Trabalho Infantil, Programa Agente Jovem de Desenvolvimento Social e Humano, Programa Bolsa Família e demais programas de transferência de renda (Art. $7^{\circ} \S 2^{\circ} \mathrm{II}$ ).

Fica evidente que a aprovação e a apuração dos dados são de responsabilidade das universidades, que lançarão seus próprios editais, observando o disposto na Portaria. É no Edital que constarão os formulários de comprovação socioeconômica, os documentos necessários, prazos, realização de entrevistas, dentre outras informações necessárias. Caso o estudante preste informação falsa, poderá ocorrer o cancelamento de sua matrícula, resguardado seu direito de contraditório e ampla defesa, sem prejuízo das sanções penais cabíveis.

\section{APROXIMAÇÕES CONCLUSIVAS}

Construir conhecimento é olhar para o processo que levou na culminação de um determinado resultado e inferir como a história e os grupos de interesses influenciam no achado. $O$ estudo apresentado talvez não tenha chegado na finitude de sua busca, mas abre caminhos para novos estudos que possam contribuir para o sistema de cotas e o acesso igualitário das camadas populares no ensino superior público.

Deve-se ter em mente que o Sistema de Cotas é um tipo de ação afirmativa, destinado a corrigir as desigualdades no acesso ao ensino superior. E que, não falar desse processo, é tornar invisível um problema educacional e social que afeta principalmente as classes menos favorecidas. Souza (2003) alega que a naturalização da desigualdade é um fator que impede a transformação. Ela se manifesta por meio do capitalismo e mascara as relações sociais, "[...] precisamente porque construída segundo as formas impessoais e peculiarmente opacas e intransparentes [...] de uma 'ideologia espontânea do capitalismo' que traveste de universal e neutro o que é contingente e particular" (SOUZA, 2003, p. 179).

As cotas, mesmo que reparatórias e paliativas, também pertencem à revolução. A transformação acontece de forma molecular, mas não deixa de ser alicerce para novas mudanças, novas transformações. Inserir as camadas menos favorecidas no ensino superior é permitir que todos tenham acesso a esse nível de educação.

Mas essa mudança não deve acontecer primeiramente no ensino básico? É o discurso de muitos. Mas não, uma mudança não exclui a outra. Garantir a qualidade de educação deve acontecer em todos os níveis de ensino, inclusive no ensino superior. Não se deve esquecer a universidade! Muitos estão ingressando nela agora, ou querem ingressar e dependem de políticas que tratem de forma desigual os desiguais. Políticas que deem oportunidades aos que não as tiveram.

Devem-se pensar alternativas, programas e capacitações para os professores e profissionais envolvidos na educação básica para que se alcance a qualidade desejada. Mas também, em políticas de acesso ao ensino superior para os que não tiveram acesso a essa qualidade na atual conjuntura. 
Feres Júnior, Daflon e Campos (2012) ainda vão além, quando se trata de avaliar o atual Sistema de Cotas, descrevendo que o texto da Lei fala da reserva de vagas, e não da ocupação de vagas, preservando a autonomia da universidade, o que "[...] pode resultar na não ocupação das vagas destinadas aos alunos cotistas" (FERES JÚNIOR; DAFLON; CAMPOS, 2012, p. 408). O autor aborda também o critério do aluno ter cursado integralmente o ensino médio em escolas públicas, o que exclui candidatos que tenham feito, por exemplo, “[...] progressão rápida em escolas privadas, o que é comum em candidatos mais velhos que precisam trabalhar" (FERES JÚNIOR; DAFLON; CAMPOS, 2012, p. 409). Sem falar que:

A lei é completamente silente a respeito da grande heterogeneidade da qualidade das escolas públicas em nosso país. Isso porque candidatos de algumas escolas de ensino médio federal e de colégios militares e de aplicação, que não raro adotam processos altamente seletivos de admissão, podem se beneficiar da reserva de vagas, constituindo assim uma competição altamente desigual para outros cotistas (FERES JÚNIOR; DAFLON; CAMPOS, 2012, p. 409).

Enfim, diante de algumas lacunas deixadas pelo sistema de cotas, é preciso repensar e rever os critérios, para que as vagas sejam ocupadas por estudantes que necessitem delas. Enquanto isso, o ingresso nas universidades públicas permanece meritocrático e seletista. Grande parte do alunado ainda pertence às frações de classe que tiveram acesso a um ensino que lhe deu base para o vestibular, ou ainda são aqueles que fizeram cursinho preparatório. Por que grande parte dos alunos de ensino básico público está nas universidades privadas, por vezes, pagando sua graduação, ou contratando financiamento para pagar anos e anos? Será que esses alunos não conseguiram acessar a universidade pública?

O cenário sempre se inverte. No ensino básico, todos querem estar em escolas privadas; no ensino superior, todos querem ingressar em universidades públicas. Portanto, o trabalho é necessário em todos os âmbitos, melhorar a educação pública básica influi diretamente no ensino superior. Haver cotas nas universidades, para alunos de escolas públicas, repara essa lacuna da educação e insere esses alunos no ensino superior público.

As cotas são oportunidades para muitos, mas é preciso salientar que elas não devem ser uma medida permanente, senão nunca haverá mudança. Elas são reparatórias de um panorama de profunda desigualdade. Logo, falar de cotas é discutir o acesso das camadas populares na universidade, tema de um próximo artigo, mas primordial para entender que retomar a historicidade é extremamente relevante para a promoção da educação pública, gratuita e de qualidade.

\section{REFERÊNCIAS}

BENINCÁ, Dirceu. Universidade e suas fronteiras. São Paulo: Outras Expressões, 2011.

BEZERRA, Teresa Olinda Caminha; GURGEL, Claudio. A política pública de cotas em universidades, desempenho acadêmico e inclusão social. Sustainable Business 
International Journal, Rio de Janeiro, n. 9, p. 1-22, ago. 2011. Disponível em: <http://www.sbijournal.uff.br/index.php/sbijournal/article/view/15/10>. Acesso em: 29 mar. 2017.

BOURDIEU, P. Escritos de educação. 10. ed. Petrópolis: Vozes, 2014.

BRAGA, Delma Coelho. Uma análise da política de cotas na Universidade Federal do Pará. 2014. 69 f. Monografia (Especialização em Gestão Universitária) -Curso de Especialização em Gestão Universitária do Núcleo de Altos Estudos Amazônicos da Universidade Federal do Pará, Belém, 2014. Disponível em:

<http://www.naea.ufpa.br/naea/novosite/index.php?action=Tcc.arquivo\&id=343>. Acesso em: 14 jun. 2017.

BRASIL. Presidência da República. Decreto n. 7.824, de 11 de outubro de 2012. Regulamenta a Lei $\mathrm{n}^{0} \mathbf{1 2 . 7 1 1}$, de 29 de agosto de 2012, que dispõe sobre o ingresso nas universidades federais e nas instituições federais de ensino técnico de nível médio. Diário Oficial da União, Brasília (DF), 15 out. 2012b. Disponível em: <http://www.planalto.gov.br/ccivil_03/_ato2011-2014/2012/Decreto/D7824.htm>. Acesso em: 27 out. 2015 .

BRASIL. Presidência da República. Lei n. 12.711, de 29 de agosto de 2012. Dispõe sobre o ingresso nas universidades federais e nas instituições federais de ensino técnico de nível médio e dá outras providências. Diário Oficial da União, Brasília (DF), 30 ago. 2012a. Disponível em: <http://www.planalto.gov.br/ccivil_03/_ato2011-2014/2012/lei/l12711.htm>. Acesso em: 15 abr. 2015.

BRASIL. Ministério da Educação. Portaria Normativa n. 18, de 11 de outubro de 2012. Dispõe sobre a implementação das reservas de vagas em instituições federais de ensino de que tratam a Lei $n^{\circ} 12.711$, de 29 de agosto de 2012, e o Decreto $n^{\circ} 7.824$, de 11 de outubro de 2012. Diário Oficial da União, Brasília (DF), 15 out. 2012c. Disponível em: <http://portal.mec.gov.br/cotas/docs/portaria_18.pdf>. Acesso em: 27 out. 2015.

BRASIL. Supremo Tribunal Federal: jurisprudência. Arguição de descumprimento de preceito fundamental 186. Brasília (DF), 26 abr 2012. Disponível em: <http://redir.stf.jus.br/paginadorpub/paginador.jsp?docTP=TP\&docID=6984693>. Acesso em: 15 abr. 2017.

BRASIL. Supremo Tribunal Federal: jurisprudência. Ação direta de inconstitucionalidade: 3330. Brasília (DF), 03 mai 2012. Disponível em:

<https://stf.jusbrasil.com.br/jurisprudencia/14772029/acao-direta-de-inconstitucionalidadeadi-3330-df-stf>. Acesso em: 15 abr. 2017.

CUNHA, Luiz Antônio. Qual universidade? São Paulo: Cortez; Autores Associados, 1989.

DEMO, Pedro. A nova LDB: ranços e avanços. 22. ed. Campinas: Papirus, 1997. 
DIAS, Alvaro Fernandes. Projeto de Lei do Senado n. 479, de 16 de dezembro de 2008. Reserva $20 \%$ das vagas dos vestibulares para os cursos de graduação das universidades públicas federais e estaduais para estudantes oriundos de família com renda per capita familiar de até um salário mínimo e meio. Diário do Senado Federal, Brasília (DF), 17-18 dez. 2008. Disponível em: <https://www25.senado.leg.br/web/atividade/materias//materia/88773>. Acesso em: 28 jan. 2017.

EM 2003, UERJ se torna a primeira universidade do país a adotar cotas. G1, Rio de Janeiro, 3 ago. 2013. Disponível em:

<http://redeglobo.globo.com/globouniversidade/noticia/2013/08/em-2003-uerj-se-tornaprimeira-universidade-do-pais-adotar-cotas.html>. Acesso em: 12 jan. 2017.

FERES JÚNIOR, João; DAFLON, Verônica Toste; CAMPOS, Luiz Augusto. Ação afirmativa, raça e racismo: uma análise das ações de inclusão racial nos mandatos de Lula e Dilma. Revista de Ciências Humanas, Viçosa, v. 2, n. 2, p. 399-414, jul./dez. 2012. Disponível em: <http://www.cch.ufv.br/revista/pdfs/vol12/artigo8vol12-2.pdf>. Acesso em: 5 abr. 2017.

LOBÃO, Abdenice. Projeto de Lei da Câmara n. 180, de 25 de novembro de 2008. Lei de Cotas Sociais. Dispõe sobre o ingresso nas universidades federais e estaduais e nas instituições federais de ensino técnico de nível médio e dá outras providências. Diário do Senado Federal, Brasília (DF), 26 nov. 2008. Disponível em:

<https://www25.senado.leg.br/web/atividade/materias/-/materia/88409>. Acesso em: 28 jan. 2017.

MADRUGA, Sidney. Discriminação positiva, ações afirmativas na realidade brasileira. Brasília (DF): Brasília Jurídica, 2005.

MATTOS, Leonardo José de et al. Projeto de Lei da Câmara n. 129, de 26 de junho de 2009. Dispõe sobre a reserva de vagas para pessoas com deficiência nas instituições públicas de ensino médio e superior. Diário do Senado Federal, Brasília (DF), 27 jun. 2009. Disponível em: <https://www25.senado.leg.br/web/atividade/materias/-/materia/91854>. Acesso em: 28 jan. 2017.

MENEZES, Paulo Lucena de. A ação afirmativa no direito norte-americano. São Paulo: Revista dos Tribunais, 2001.

MINISTÉRIO DA EDUCAÇÃO. Estudantes: REUNI: Programa de Apoio a Planos de Reestruturação e Expansão das Universidades Federais (Reuni). Brasília, DF, 2017. Disponível em: <http://portal.mec.gov.br/reuni-sp-93318841>. Acesso em: 28 jan 2017.

NASCIMENTO, Alexandre do et al. 120 anos da luta pela igualdade racial no Brasil: manifesto em defesa da justiça e constitucionalidade das cotas. Brasília (DF), 13 maio 2008. Disponível em: <http://www.ceap.br/material/MAT27102009124409.pdf>. Acesso em: 29 mar. 2017. 
NASCIMENTO, Alfredo Pereira do. Projeto de Lei do Senado n. 971, de 2015. Altera a Lei ${ }^{\circ}$ 8.078, de 11 de setembro de 1990 (Código de Defesa do Consumidor), para vedar à instituição financeira a realização de débito em contas de depósito sem prévia autorização do consumidor. Diário do Senado Federal, Brasília (DF), 2015. Disponível em: <http://www.camara.gov.br/sileg/integras/1321768.pdf>. Acesso em: 28 jan. 2017.

PERILLO JÚNIOR, Marconi Ferreira. Projeto de Lei do Senado n. 344, 10 de setembro de 2008. Institui reserva de vagas nos cursos de graduação das instituições públicas de educação superior, pelo período de doze anos, para estudantes oriundos do ensino fundamental e médio públicos. Diário do Senado Federal, Brasília (DF), 11 set. 2008. Disponível em: <https://www25.senado.leg.br/web/atividade/materias/-/materia/87354>. Acesso em: 28 jan. 2017.

PODER EXECUTIVO. Projeto de Lei n. 3.627/2004, de 20 de maio de 2004. Institui Sistema Especial de Reserva de Vagas para estudantes egressos de escolas públicas, em especial negros e indígenas, nas instituições públicas federais de educação superior e dá outras providências. Diário da Câmara dos Deputados, Brasília (DF), 2 jun. 2004. Disponível em: <http://www.camara.gov.br/proposicoesWeb/fichadetramitacao?idProposicao=254614>. Acesso em: 15 abr. 2016.

ROZAS, Luiza Barros. Cotas para negros nas universidades públicas e a sua inserção na realidade jurídica brasileira - por uma nova compreensão epistemológica do princípio constitucional da igualdade. 2009. Dissertação (Mestrado em Direito) - Faculdade de Direito, Universidade de São Paulo, São Paulo, 2009. Disponível em:

<https://www.google.com.br/url?sa=t\&rct=j\&q=\&esrc=s\&source=web\&cd=2\&cad=rja\&ua $\mathrm{ct}=8 \&$ ved=0ahUKEwif8 KbBz_vSAhVMGZAKHW 5vBhQQFggkMAE\&url=http\%3A\%2F\%2Fww w.teses.usp.br\%2Fteses\%2Fdisponiveis\%2F2\%2F2140\%2Ftde-21062011-

153542\%2Fpublico\%2FLuiza_Barros_Rozas_Dissertacao.pdf\&usg= AFQjCNFRoPKAeEL_NdHpoM31aqbB1V3YA\&sig2=nZm3Kf6Ffx743CPVtJmThw \&bvm=bv.150729734,d.Y2l>. Acesso em: 29 mar. 2017.

SALVATTI, Ideli. Projeto de Lei n. 3.913, de 20 de agosto de 2008. Institui o sistema de reserva de vagas para estudantes egressos de escolas públicas nas instituições federais de educação superior, profissional e tecnológica. Diário da Câmara dos Deputados, Brasília (DF), 5 set. 2008. Disponível em:

<http://www.camara.gov.br/proposicoesWeb/fichadetramitacao?idProposicao $=407880>$. Acesso em: 15 abr. 2016.

SERAFIM, Milena Pavan; DIAS, Rafael de Brito. Análise de política: uma revisão da literatura. Cadernos de Gestão Social, Salvador, v. 3, p. 121-134, jan./jun. 2012.

SOUZA, Jessé. A construção social da subcidadania: para uma sociologia política da modernidade periférica. Belo Horizonte: Universidade Federal de Minas Gerais; Rio de Janeiro: Instituto Universitário de Pesquisas do Rio de Janeiro, 2003. 
SOUZA, Jessé. Ralé brasileira: quem é e como vive. Belo Horizonte: Universidade Federal de Minas Gerais, 2009.

UNIVERSIDADE DE BRASÍLIA. Análise do sistema de cotas para negros da Universidade de Brasília: período $2^{\circ}$ semestre de 2004 ao $1^{\circ}$ semestre de 2013. Brasília (DF), 2013. 